\title{
Premenstrual Syndrome and Premenstrual Dysphoric Disorder in Medical and Nursing Students of a Tertiary Care Teaching Hospital in Nepal
}

\author{
Aryal $\mathrm{S}^{1}$, Thapa $\mathbf{B}^{2}$, Pant $\mathrm{SB}^{3}$ \\ ${ }^{1}$ Department of Obstetrics and Gynaecology, Lumbini Medical College Teaching Hospital, Palpa Nepal. Lecturer, ${ }^{2}$ Department of \\ Obstetrics and Gynaecology, Lumbini Medical College Teaching Hospital, Palpa Nepal, ${ }^{3}$ Department of Psychiatry and Mental Health, \\ Tribhuwan University Teaching Hospital
}

Received: 14-May-2016; Accepted: 10-Apr-2016

\begin{abstract}
Aims: To determine the prevalence of premenstrual syndrome and premenstrual dysphoric disorder and their association with psychiatric caseness and dysmenorrhea in students of Lumbini Medical College, Palpa, Nepal.

Methods: This is a cross-sectional study where self-report questionnaires based on American College of Obstetrics and Gynecology and Diagnostic and Statistical Manual of Mental Disorders-V criteria for PMS and PMDD and the General Health Questionnaire-12 for psychiatric caseness were filled by the students. The results were calculated using SPSS 16.0 as frequencies, mean, standard deviation and chi square with a p-value of $\leq 0.05$ as significant.
\end{abstract}

Results: There were 382 participants out of which 113 (61.1\%) medical and 126 (64\%) nursing students met the ACOG criteria for PMS. PMDD was diagnosed in $78(39.6 \%)$ nursing students and 72(38.9\%) medical students. The most common somatic symptom was headache $256(77 \%)$ and behavioral symptom was irritability $310(81.2 \%)$. A significant relation (p value $\leq 0.05$ ) was seen between psychiatric caseness, dysmenorrhoea and PMS/PMDD.

Conclusion: PMS and PMDD are common in young medical and nursing students. A significant relation was present between PMS and psychiatric caseness and dysmenorrhea therefore comprehensive efforts should be made by healthcare providers to screen and manage symptoms including dysmenorrhea efficiently, thereby improving daily functioning, academic performance and professional skills of the students.

Keywords: dysmenorrhea; medical students; premenstrual syndrome; premenstrual dysphoric disorder

DOI: http://dx.doi.org/10.3126/njog.v12i1.18975

\section{INTRODUCTION}

It is common for women in reproductive age group to feel discomfort a few days prior to the onset of menses. These symptoms when start to affect the daily activities of living it is known as premenstrual syndrome. Premenstrual syndrome (PMS) is defined as distressing physical, psychological and behavioral symptoms not caused by organic disease, which regularly occurs during the same phase of menstrual cycle and significantly regresses or disappears during the remainder of the cycle. ${ }^{1}$ Premenstrual dysphoric disorder (PMDD) is a severe form of PMS with specific focus on affective symptomatology. ${ }^{2}$ There are a few associated risk factors like exercise habits, smoking, use of alcohol, altered trans-capillary fluid

\section{CORRESPONDENCE}

Dr. Shreyashi Aryal,

Lecturer, Department of Obstetrics and

Gynaecology, Lumbini Medical

College Teaching Hospital, Palpa Nepal.

Email: shreyashiaryal@gmail.com balance, a diet rich in beef or caffeine containing beverages and stress. ${ }^{3}$

PMS is a significant public health problem among young girls which adversely affects their educational performance and emotional wellbeing. Though PMS and PMDD are recognized entities, little is known about their prevalence in younger age group. The prevalence and severity of PMS and PMDD among students of medical colleges should be known as they are under a significant amount of stress regarding their educational performance. There is also a correlation between the premenstrual symptomatology and neurotic personality. It is necessary to find the prevalence of PMDD as depression is a major symptom and suicide is a risk. ${ }^{4,5}$

\section{METHODS}

This is a cross sectional study done for a period of two months from November to December 2015 at Lumbini Medical College Teaching Hospital (LMCTH), Palpa, Nepal. 
A total of 382 female students including MBBS (148), interns (37) and nursing (197) students, who gave consent for the study were included. Students who were married, had irregular cycles for past six months, had a history of intake of any hormonal medication, or a major gynecological, psychological or medical problem were excluded from the study.

This study was done after receiving approval by the Institutional Review Committee of LMCTH and all the information of the patients was kept confidential. This study was based on the evaluation of PMS symptoms according to American College of Obstetrics and Gynecology (ACOG) criteria. ${ }^{6}$ The diagnosis of PMDD was based on Diagnostic and Statistical Manual of Mental Disorders (DSM-V). ${ }^{7}$

The preexisting psychiatric morbidity was determined using the General Health Questionnaire-12 (GHQ12). GHQ-12 is a validated tool in Nepalese context. It consists of 12 items and those participants obtaining a score of three or more were considered as having a psychiatric caseness, i.e., individual would be more likely than not $(0.51)$ to be diagnosed with psychiatric or mental problems. ${ }^{8}$

Two self-report questionnaires were filled by the students with the help of briefed volunteers. The first questionnaire was based on ACOG and DSM-V criteria for PMS and PMDD. The second was the 12item GHQ-12 to determine the preexisting psychiatric morbidity. The individual scoring more than or equal to 3 by "binary scoring" method (0-0-1-1) was labelled as psychiatric caseness.

The premenstrual questionnaire was based on the following six behavioral and four somatic symptoms; depression, angry outbursts, irritability, anxiety, confusion, social withdrawal, breast tenderness, abdominal bloating, headache and swelling of extremities. PMS was diagnosed if at least one of the 6 affective and one of the four somatic symptoms was reported five days prior to the onset of menses in the three prior menstrual cycles and ceased within four days of onset of menses. Inquiry was made on whether they had experienced these symptoms during the last six months on three or more occasions. Other inquiries included were maternal history of PMS and a family history of depression or other mental illness. PMDD was diagnosed by the DSM- 5 criteria. A score of one, two and three was assigned to each symptom rated mild, moderate and severe respectively. The score of each symptom in the premenstrual period was calculated and then the total score of PMS was calculated (total score divided by number of symptoms \{mean\} converted to percent). The score between $0 \%$ to $33 \%$ represented mild form of PMS, $33 \%$ to $66 \%$ as moderate and more than $66 \%$ as severe form of PMS.

Data was analyzed using SPSS version 16.0. Results were calculated as frequencies, mean, standard deviation and chi square with a $p$-value of $\leq 0.05$ as significant.

\section{RESULTS}

There were a total of 610 medical and nursing students at LMCTH at the time of study out of which 393 were female students. 11 students were excluded because six students had irregular menstrual cycles, two were on hormonal therapy, two were married and one had a diagnosed psychiatric illness. 185 medical and 197 nursing students gave consent to participate in the study and met the inclusion criteria.

The age group was between 16 to 21 years in nursing students and 17 to 25 years in MBBS students with the mean age of $19.88 \pm \mathrm{SD} 2.2$ years and the mean BMI of $21.32 \pm \mathrm{SD} 2.8 \mathrm{~kg} / \mathrm{m}^{2}$. The mean age of menarche, length of menstrual cycle and duration of flow was $13.2 \mathrm{yrs}, 31.5$ days and 4.9 days respectively.

A total of 113 (61.1\%) MBBS and 126 (64\%) nursing students met the ACOG criteria for PMS. Total $62.5 \%$ (239) students had PMS out of which 134(56.1\%) had mild, 105(43.9\%) had moderate and none had severe PMS. 39.2\% (150) cases met the criteria of PMDD which was diagnosed in 78(39.6\%) nursing students and in $72(38.9 \%)$ medical students.

$98.4 \%$ of students had dysmenorrhea categorized as mild in $39.5 \%$, moderate in $46.9 \%$ and severe in $12 \%$. The mean \pm S.D score on the GHQ-12 was $2.33 \pm 2.11 .154(40.3 \%)$ students were categorized as having probable psychiatric morbidity having scored 3 or more on GHQ-12.

A significant relation ( $p$ value $\leq 0.05$ ) of psychiatric caseness was seen with both PMS and PMDD. Significant relation was seen between PMS and dysmenorrhea.

The characteristics of the study subjects with and without PMS and PMDD and their correlation with dysmenorrhea and psychiatric caseness are shown in Table 1 and 2. 
Frequency of affective and somatic symptoms is shown in Table 3.

Regarding the symptomatology of PMS, the most common somatic symptom was headache and commonest behavioral symptom was irritability. The frequency of other symptoms included insomnia in $191(50 \%)$ increased appetite in 254(65.6\%), acne in $231(60.5 \%)$ and backache in 292(76.4\%) students.

\section{DISCUSSION}

The prevalence of PMS and PMDD were both higher in this study compared to other studies done in medical as well as non medical colleges. There is a wide variation in incidence of PMS diagnosed with ACOG criteria. In studies done in medical colleges in Lebanon and Saudi Arabia, prevalence was reported as $7.1 \%$ and $35.6 \%$, respectively. ${ }^{9,10}$ The higher rate

Table 1: The demographic and reproductive characteristics of the study subjects with and without PMS and their and correlation with dysmenorrhea and psychiatric caseness

\begin{tabular}{|c|c|c|c|c|}
\hline & With PMS & Without PMS & Chi square & $\mathrm{p}$ value \\
\hline Age (years) & $19.84 \pm 2.22$ & $19.97 \pm 2.27$ & & 0.588 \\
\hline BMI $\left(\mathrm{kg} / \mathrm{m}^{2}\right)$ & $21.43 \pm 2.95$ & $21.15 \pm 2.70$ & & 0.351 \\
\hline Age at menarche (years) & $13.30+2.24$ & $13.05+1.19$ & & 0.213 \\
\hline Length of cycle (days) & $31.02 \pm 6.47$ & $32.47 \pm 11.65$ & & 0.118 \\
\hline Duration of flow (days) & $4.95 \pm 1.20$ & $4.76 \pm 1.21$ & & 0.151 \\
\hline \multicolumn{5}{|l|}{ Dysmenorrhoea } \\
\hline Yes & $238(99.6 \%)$ & $138(96.5 \%)$ & \multirow[t]{2}{*}{3.673} & \multirow[t]{2}{*}{0.05} \\
\hline No & $1(0.4 \%)$ & $5(3.5 \%)$ & & \\
\hline \multicolumn{5}{|c|}{ Intensity of dysmenorrhea } \\
\hline Mild & $83(34.9 \%)$ & $68(49.3 \%)$ & \multirow{3}{*}{8.167} & \multirow{3}{*}{0.017} \\
\hline Mod & $121(50.8)$ & $58(42 \%)$ & & \\
\hline Severe & $34(14.3 \%)$ & $12(8.7 \%)$ & & \\
\hline \multicolumn{5}{|l|}{ GHQ-12 caseness } \\
\hline Yes & $112(46.9 \%)$ & $42(29.4 \%)$ & 11.376 & 0.001 \\
\hline No & $127(53.1 \%)$ & $101(70.6 \%)$ & & \\
\hline
\end{tabular}

Table 2: The demographic and reproductive characteristics of the study subjects with and without PMDD and their correlation with dysmenorrhea and psychiatric caseness

\begin{tabular}{|c|c|c|c|c|}
\hline & With PMDD & Without PMDD & Chi square & $\mathrm{p}$ value \\
\hline Present Age & $19.97 \pm 2.27$ & $19.83+2.21$ & & 0.534 \\
\hline BMI & $21.67 \pm 3.06$ & $21.11 \pm 2.70$ & & 0.070 \\
\hline Age at menarche & $13.43 \pm 2.59$ & $13.06 \pm 1.29$ & & 0.071 \\
\hline Length of cycle in days & $30.75 \pm 7.25$ & $32.09 \pm 9.62$ & & 0.146 \\
\hline Duration of flow in days & $4.93 \pm 1.21$ & $4.84 \pm \_1.21$ & & 0.518 \\
\hline \multicolumn{5}{|l|}{ Dysmenorrhoea } \\
\hline Yes & $150(100 \%)$ & $6(2.6 \%)$ & \multirow[t]{2}{*}{2.446} & \multirow[t]{2}{*}{0.118} \\
\hline No & $0(0 \%)$ & $226(97.4 \%)$ & & \\
\hline \multicolumn{5}{|c|}{ Intensity of dysmenorrhea } \\
\hline Mild & $54(36 \%)$ & $0(0 \%)$ & \multirow[b]{2}{*}{2.439} & \multirow[b]{2}{*}{0.295} \\
\hline $\begin{array}{l}\text { Mod } \\
\text { Severe }\end{array}$ & $\frac{74(49.3 \%)}{22(14.7 \%)}$ & $\frac{3(50 \%)}{3(50 \%)}$ & & \\
\hline \multicolumn{5}{|l|}{ GHQ-12 Caseness } \\
\hline Yes & $81(54.0 \%)$ & $73(31.5 \%)$ & 19.226 & $<0.001$ \\
\hline No & $69(46.0 \%)$ & $159(68.5 \%)$ & & \\
\hline
\end{tabular}

Table 3: Frequency of symptoms according to ACOG criteria.

\begin{tabular}{|l|l|}
\hline Affective Symptoms & $\mathbf{n}(\%)$ \\
\hline Depression & $186(48.7)$ \\
\hline Angry outburst & $301(62)$ \\
\hline Irritability & $310(81.2)$ \\
\hline Anxiety & $301(78.8)$ \\
\hline Confusion & $190(49.7)$ \\
\hline
\end{tabular}

\begin{tabular}{|l|l|}
\hline Social Withdrawal & $167(43.7)$ \\
\hline Somatic Symptoms & $\mathbf{n ~ ( \% )}$ \\
\hline Breast tenderness & $235(61.5)$ \\
\hline Abdominal bloating & $182(47.6)$ \\
\hline Headache & $256(77)$ \\
\hline Swelling of extremities & $118(30.9)$ \\
\hline
\end{tabular}


of $62.5 \%$ in this study could be due to geographical and cultural variation since the prevalence of PMS in students in Nepal is not known.

The prevalence of PMDD reported as 39.2\% in this study as per DSM-V criteria is higher than $36.2 \%$ and $16.9 \%$ reported in a study done in Nigeria by Issa et al and by Nourjah in Iran. ${ }^{11,12}$ A low rate of $12 \%$ was reported in Pakistan by Nisar et $\mathrm{al}^{13}$ and even lower prevalence of $1.2 \%$ was shown by Takeda et $\mathrm{al}^{14}$ in non medical high school students in Japan. Psychiatric caseness is one associated factor for the diagnosis of PMDD which was seen in $40.3 \%$ students. The presence of other confounding factors like emotional disturbance not attributed to menses were not looked for and other medical conditions were not screened for which could have been the reason for higher rates of PMDD.

In this study, there were no cases of severe PMS whereas rate of PMDD is high because of the use of two different criteria to diagnose these two conditions. There are no specific tests to diagnose these PMS/PMDD so we have to depend on various diagnostic criteria which have some overlapping in them. DSM-V criteria focuses more on affective symptomatology and our study subjects had more of these symptoms so a high rate of PMDD could have been reported.

The reason for higher rates for both PMS and PMDD could also be due to the retrospective recording of symptoms and recall bias of students and their tendency to exaggerate symptoms while filling the questionnaires.

Rate of PMS was high in nursing students as they are of younger age group in their late adolescence which is a vulnerable age. Takeda et al reported in their study that PMS is common in teenagers than in adults. ${ }^{14}$

The correlation between probable psychiatric morbidity and PMDD was significant.

Psychiatric morbidity according to GHQ-12 was $40.3 \%$ in this study with a significant relationship with PMS and PMDD which is higher than the 20.2\% reported by Issa B et al. where no causal relationship with PMDD was made. ${ }^{11}$ The high rate of PMDD in this study could be due to high prevalence of psychiatric caseness. Also there was significant relation between dysmenorrhea and PMS which could mean that dysmenorrhea aggravates menstrual symptoms or those students with dysmenorrhea report more of PMS symptoms.

The commonest affective symptom in this study was irritability (81.2\%) which is similar to $71.8 \%$ reported by Attieh et $\mathrm{al}^{9}$ and $71.05 \%$ by Sitwat et al. ${ }^{15}$

The most common somatic symptom was headache (77\%) in this study whereas Lebanese and Egyptian medical students cited breast tenderness as the most common. ${ }^{9,16}$ Bakr et al reported insomnia in $60 \%$ of the students and this study showed 50\% students had insomnia. ${ }^{16}$ This is a significant finding as insomnia prevents effective working capacity and may cause professional mistakes.

This was a cross sectional study and the prospective study for two further cycles as stated by ACOG criteria could not be done. This study was based on questionnaire method so students may have amplified the symptoms due to recall bias. Also, a standard pain assessment method for dysmenorrhea would be more desirable.

\section{CONCLUSIONS}

PMS and PMDD are common in Nepalese medical students and more common in young nursing students. High rates could be attributed to probable pre existing psychiatric morbidity and the stress of medical education. A significant correlation was present between PMS and psychiatric caseness and dysmenorrhea therefore comprehensive efforts should be made by health care providers to screen and manage symptoms including dysmenorrhea efficiently, thereby improving daily functioning, academic performance and professional skills of the students.

\section{ACKNOWLEDGEMENTS}

We are much grateful to all the students who participated in the study.

\section{DISCLOSURE}

The authors report no conflicts of interest in this work. No violation of human rights and safety.

Funding: Nil 


\section{REFERENCES}

1. Wilhelm H, Cronje A, Studd J. Premenstrual syndrome. In: Studd J, editor. Progress in Obstetrics and Gynecology, vol 15. 1st ed. London: Churchill Livingstone 2003. p. 169-83.

2. Freeman EW, Sondheimer SJ. Premenstrual dysphoric disorder: recognition and treatment. Prim Care Companion J Clin Psychiatry. 2003;5: 30-9.

3. Yonkers KA, O'Brien PM, Eriksson E. Premenstrua syndrome. The Lancet. 2008;371: 1200-10.

4. Dalton K. The premenstrual syndrome. The Lancet 1965;285: 1392 .

5. Mandell AJ, Mandell MP. Suicide and the menstrual cycle. JAMA. 1967; 200: 792-93.

6. American College of Obstetrics and Gynecology. ACOG practice bulletin: premenstrual syndrome. Washington D.C: ACOG. 2000:15.

7. American Psychiatric Association. Diagnostic and Statistical Manual of Mental Disorders. 5th edition. American Psychiatric Association, Washington, D.C. 2013.

8. Khattri JB, Poudel B, Godar S, Tirkey S, Ramesh K et al An epidemiological study of psychiatric cases in a rura community of Nepal. Nepal J Med Sc. 2013;2: 52-6.
9. Attieh E, Maalouf S, Richa S, Kesrouani A. Premenstrua syndrome among Lebanese medical students and residents. Int J Gynaecol Obstet. 2013;121: 184-5.

10. Balaha M, Abd El Monem Amr M, Saleh Al Moghannum M, Saab Al Muhaidab N. The phenomenology of premenstrual syndrome in female medical students: a cross sectional study. Pan Afr Med J. 2010; 5: 4.

11. Issa BA, Yussuf AD, Olatinwo AW, Ighodalo M. Premenstrual dysphoric disorder among medical students of a Nigerian university. Ann Afr Med. 2010;9: 118-22.

12. Nourjah P. Premenstrual syndrome among Teacher Training University students in Iran. J Obstet Gynecol India. 2008;58: 49-52.

13. Nisar N, Zehra N, Haider G, Munir AA, Sohoo NA. Frequency, intensity and impact of premenstrual syndrome in medical students. J Coll Physicians Surg Pak. 2008; 18: 481-4.

14. Takeda T, Koga S, Yaegashi N. Prevalence of premenstrual syndrome and premenstrual dysphoric disorder in Japanese high school students. Arch Women Ment Health. 2010;13: 535-7.

15. Sitwat Z, Abid A, Arif A, Basit A, Anwar QM. Premenstrual syndrome symptoms (PMS) and prevalence among university students in Karachi, Pakistan. Int Res J Pharm. 2013; 4: 113-6.

16. Bakr I, Ez-Elarab HS. Prevalence of premenstrual syndrome and the effect of its severity on the quality of life among medical students. Egypt J Community Med. 2010;28: 19-30. 